\title{
REESTRUCTURACIÓN AGRARIA Y ABANDONO DE USOS: EL CASERÍO VASCO
}

\author{
Juan Cruz Alberdi Collantes \\ Departamento de Geografía, Prehistoria y Arqueología \\ Universidad del País Vasco
}

\section{RESUMEN}

En este artículo analizamos las consecuencias que la concentración de la capacidad productiva en un reducido número de explotaciones va a tener sobre los usos del suelo del caserío vasco. Observamos cómo van a ser muy pocas las explotaciones agroganaderas que van a continuar y menos aún las que se van a ver necesitadas de suelo agrícola. Como resultado, a medio plazo, una vez que se consolide el proceso que lleva al abandono definitivo de la mayoría de las unidades productivas actuales, las tierras más alejadas de zonas próximas a ganaderías y las que no pueden ser objeto de maquinaria agrícola dejarán paso a la regeneración de la cubierta vegetal.

Palabras clave: caserío, San Sebastián, País Vasco, agricultura, ganadería usos del suelo, extensificación.

\begin{abstract}
In this paper we study the changes in the rural landscape as a consequence of production concentration in a small number of explotations. We see that the number of explotations will continue be very little. In fact, in a half time-limit, when the process is also consolity, the fartherst farm flour to the cow explotation and the flour that can't be mecanized will be ease. In that space, the regeneration of natural vegetation will begin.
\end{abstract}

Key words: San Sebastian, Basque Country, agriculture, cattle, use of the flour, extensification.

La política agraria actual trata de incorporar el sector agrícola al funcionamiento del sistema capitalista, regulado por las leyes de la oferta y la demanda. Se concreta en una apuesta evidente por la consecución de un sector moderno, productivo y capaz de competir en un mercado cada vez más liberalizado. 
En un ámbito más cercano, es la política agraria comunitaria (P.A.C.) la que va a dirigir la expansión capitalista en la agricultura. Se impulsa un modelo de explotación centrado en unas actividades especializadas, capitalizadas y orientadas al crecimiento de la rentabilidad. Surgen unidades agrarias más eficientes, capaces de hacer frente a la baja de precios que un mercado más liberalizado origina. La capacidad productiva, sin embargo, se concentra en un reducido número de instalaciones, mientras otras muchas inician un camino hacia el abandono de la agricultura.

La incidencia de este proceso en caserío vasco se concreta en una reducción intensa del número de unidades agroganaderas, en un cambio en la orientación productiva con una apuesta por actividades más extensivas (de vacuno de leche a carne), en una falta de relevo al frente de la unidad familiar generalizada e incluso en la pérdida de algunos de los atributos que habían caracterizado a su medio social, como el mayorazgo o el trabajo comunitario.

Los usos del suelo, sin embargo, no reflejan aparentemente las consecuencias de este proceso de reestructuración agrícola y el bosque, la pradera y el pasto ocupan extensiones similares, sin apenas alteraciones desde mediados de la década de los años setenta ${ }^{1}$.

En este artículo, tomando como referencia la evolución que presentan aquellos aspectos que definen la continuidad de los usos del suelo de un área ordenada en torno al caserío vasco, el periurbano de San Sebastián o comarca de Donostialdea-Bidasoa, vamos a indagar en la tendencia que muestran sus usos del suelo del medio rural, tratando de comprobar si los aprovechamientos actuales mantendrán su presencia o, por el contrario, si presentarán alteraciones e incluso si se va a perder extensión agrícola utilizable.

\section{La evolución de los usos agrícolas en zonas de montaña y periurbanas apuntan una reducción de la superficie utilizada}

El desnivel, junto con la altitud y las dificultades climáticas, lleva a la Unión Europea a delimitar una serie de áreas caracterizadas por presentar unas condiciones físicas más desfavorables para el desarrollo agroganadero, recogidas bajo la denominación de agricultura de montaña, entre las que se incluye la comarca de Donostialdea-Bidasoa.

En un trabajo de investigación promovido por EUROMONTANA (1997), se recoge información relativa a los problemas medioambientales originados por los procesos de cambio que en los últimos años se están desarrollando en la actividad agroganadera².

Se observa, prácticamente en todas las regiones, una clara bipolarización entre aquellas áreas que soportan una sobreexplotación, con una intensificación de los aprovecha-

1 Comparando la distribución de usos (Ha.) que los inventarios forestales de 1986 y 1996 realizan, sobre un total de $37.855 \mathrm{Ha}$. inventariadas en 1986 y un total de 37.859 en 1996 en la comarca de Donostialdea-Bidasoa, 10.786 Ha. en 1986 y 11.032 Ha. en 1996 son S.A.U., mientras el espacio forestal ocupa 17.140 y 16.857 Ha. respectivamente (Departamento de Agricultura y Pesca del Gobierno Vasco. Inventario Forestal 1986, p. 47; Inventario Forestal 1996, pp. 188 y 191). Otras publicaciones relativamente recientes tampoco observan cambios en los usos del suelo agrario. En la encuesta sobre la estructura de las explotaciones agrarias de 1990 y 1997 para la provincia de Gipuzkoa, la única diferencia significativa observada entre 1990 y 1995 es el aumento de las tierras de cultivo en cerca de $1.200 \mathrm{Ha}$. a cuenta de los prados y pastizales. Terreno forestal y otras superficies apenas presentan alteraciones inferiores a $100 \mathrm{Ha}$.

2 En el trabajo se analizan un total de 24 zonas de montaña europeas clasificadas en seis grandes áreas: montañas secas mediterráneas, regiones nórdicas, Alpes centrales y orientales, Alpes occidentales, regiones oce- 
mientos agrarios, y aquellas otras que son infrautilizadas y a menudo abandonadas. Las razones que lo provocan son múltiples. Entre otras cabe señalar la pérdida de rentabilidad de la producción tradicional que lleva a adoptar actitudes tendentes a aumentar la carga ganadera por encima de los recursos forrajeros que obtiene la unidad agraria, a partir de la compra a bajo precio de aportes alimenticios originarios de zonas más llanas y alejadas, desechando a menudo la cosecha local por escasa productividad. La falta de mano de obra y de formación también son argumentos apuntados, especialmente la primera, que impide utilizar determinados terrenos por carencia de tiempo. Todo ello genera un abandono de las superficies marginales y una concentración de la actividad en los mejores suelos ${ }^{3}$.

Donostialdea-Bidasoa, además de constituir una zona de montaña con unos aprovechamientos condicionados por la pendiente también es una comarca sometida a la presión del medio urbano. La proximidad a la ciudad influye en la configuración del espacio productivo y en los cambios en los aprovechamientos del suelo agrario. En nuestro caso, al menos se han de tener en cuenta dos aspectos:

- Si en zonas de montaña el abandono de explotaciones es superior al habitual de los países industrializados, en las áreas periurbanas también se genera un fenómeno de estas magnitudes. Junto al abandono, la extensificación de usos es otro atributo común a ambas zonas. Los fenómenos de intensificación y especialización de una parte de las explotaciones agroganaderas también son comunes.

- La diferencia sustancial la establece la presión urbana. En estas zonas, las tierras no utilizadas en propiedad son arrendadas o cedidas, normalmente bajo la fórmula de contratos en precario, que potencian el desarrollo de unos aprovechamientos extensivos. Así, la extensificación y el abandono se puede generalizar, incluso en las parcelas que mejores condiciones agrológicas presentan.

En este marco general hemos de encuadrar, a priori, los posibles cambios que en los próximos años se van a producir en los usos del suelo agrícola de la comarca de Donostialdea-Bidasoa y que, en todos los casos, parecen marcar una reducción del suelo utilizable a añadir a aquel que, consecuencia de la presión urbana, pasará a ser clasificado como urbano.

\footnotetext{
ánicas y Pirineos centrales. En cada región han sido tomadas como muestra una serie de áreas concretas. En la región de las montañas secas mediterráneas Vardousia, Juchtas Strubulas, Pyrénées méditerranées, Massif Central Sud, Fra Parchi e montagna interna, Lucata, Penibética, Terra Quente y Alto Douro. En las regiones nórdicas Caringorma, Vindeln, Nsavo. En los Alpes Centrales y Orientales Tyrol Oberland, Triglav, Val di Cembra, Canton d'Appenzall, Oberallgäu. En los Alpes Occidentales Beaufort, Aosta, Canton du Valais, Vercois, Jura. En las regiones oceánicas Picos de Europa y zonas limítrofes, la Montaña Vasco-Francesa y diversas regiones clasificadas 5b en el País Vasco-Español. En el Pirineo Central Haut Couserans y Sobrarbe.

3 Son muchos los trabajos que sobre zonas de montaña insisten en la bipolarización de usos que apuntamos. Para más información consultar REPARAZ (1992) sobre la región de Prealpes del Sur, FJELLSTAD et DRAMSTAD (1999) sobre Noruega, ARNAEZ et al. (1989) sobre el Sistema Ibérico, ... Se puede señalar que las zonas de agricultura de Montaña de España responden a este modelo, o al menos así lo deducimos de las aportaciones que LASANTA realiza: «La evolución reciente de los sistemas de gestión en las montañas españolas muestran una utilización diferencial del territorio, con intensificación de los mejores enclaves, tanto agrícolas como ganaderos, y extensificación del resto del espacio. Ello suponía una dependencia excesiva de una pequeña parte del territorio y un desaprovechamiento del resto de los recursos disponibles» (1996, p. 19).
} 


\section{El periurbano de San Sebastián presenta los primeros indicios de abandono}

Con el objeto de definir las transformaciones que se van a producir en el manejo del suelo agrícola utilizable de Donostialdea-Bidasoa vamos a analizar en primer lugar el equilibrio actual de estas prácticas, atendiendo a las posibilidades de mecanización del terreno agrícola ${ }^{4}$.

\subsection{Utilización del espacio agrícola: situaciones planteadas}

El análisis de los caseríos de un municipio de las proximidades de San Sebastián, Usurbil, constituye una muestra lo suficientemente amplia como para reflejar las distintas posiciones que se plantean actualmente en la utilización del espacio agrícola.

En la entrevista se les preguntaba sobre los terrenos que utilizaban tanto en propiedad como en arrendamiento o cesión. En 137 casos respondieron a esta cuestión y, en función de la réplica, observamos distintos comportamientos. Recogemos a continuación las líneas principales que contrastamos:

- La de aquellas explotaciones que carecían de actividad agroganadera. En todas ellas habían abandonado esta función y cedían o arrendaban sus terrenos. En muchos casos poseían suelos no agrícolas en los que dominaban las repoblaciones de coníferas. En Usurbil encontramos 16 caseríos sin ninguna actividad reseñable.

- La de aquellas en las que la actividad era regresiva o marginal. En esta situación estaban 60 de las explotaciones entrevistadas. La labor agroganadera era sensiblemente inferior a la equivalencia de una unidad de trabajo agrícola (U.T.A.). Estas, sin embargo, planteaban comportamientos distintos:

- Un pequeño grupo, 7 caseríos, presentaba una ocupación muy marginal, normalmente una o dos unidades de ganado mayor (U.G.). Aprovechaban algo de su heredad pero, por lo general, cedían o arrendaban el uso del resto.

- Un conjunto más numeroso, 32 explotaciones, con 2 ó 3 U.G. de media, no prescindía de sus terrenos. El espacio agroganadero estaba infrautilizado y suelos con unas buenas condiciones agrológicas habían pasado de prado a pasto ${ }^{5}$.

4 En un momento de falta de mano de obra son los terrenos no mecanizables los que primero se abandonan. Por ello, consideramos apropiado realizar esta diferenciación. En el mismo sentido, se pronuncian otros investigadores. RUIZ URRESTARAZU señala cómo «la superficie de suelo disponible está directamente relacionada con la pendiente que, como ya se ha dicho, es muy acusada en toda la vertiente atlántica a causa de su morfología topográfica. Se puede considerar de manera empírica que el máximo de pendiente aceptable en esa zona para una actividad agraria mecanizada, que es la única que va a subsistir, se establece en el $20 \%$. El porcentaje de superficie que se incluye dentro de ese nivel de pendiente de hasta el $20 \%$ abarca el $32,7 \%$ en Bizkaia y sólo el 20,1\% en Gipuzkoa» (1999, p. 3).

5 El paso de prado a pasto no marca necesariamente una pérdida de productividad por lo que en principio no deberíamos de referirnos a este proceso como subexplotación o infrautilización. AMELLA, et al. señalan que «cualquier sistema de pastoreo bien conducido puede proporcionar buena productividad del pasto. Es la estructura de la explotación la que inicialmente determina el método a elegir» (1990, p. 113). Sin embargo, al analizar la explotación de pasto en los caseríos guipuzcoanos, los mismos autores apuntan que el pastoreo no se conduce adecuadamente en estas zonas. Es necesario un sistema racionado que requiere adiestramiento y costumbre y que, dadas las características de la población activa, es descartable en muchas explotaciones (1990, p. 104). En esta investigación hemos observado qué tipo de explotaciones son las que reducen la carga ganadera y en ellas el adiestramiento de su población en técnicas que no conocen no se ha dado, por lo que consideramos que el paso de prado a pasto supone una pérdida de la capacidad productiva del suelo tanto en materia seca como en unidades forrajeras. 
- Las últimas 21 unidades no sólo no cedían los suyos sino que incluso utilizaban parcelas de otros. En casi todos los casos se trataba de caseríos en los que el jefe ostentaba una ocupación exclusiva pero, ya jubilado, veía cómo nadie continuaba con la actividad y optaba por disminuir el número de cabezas y por labores más extensivas. Aunque no solían ser muchos los terrenos utilizados que no eran de su propiedad, tanto en unos como en otros la subexplotación era evidente.

- La de aquellas explotaciones con una función agroganadera asentada. En este grupo englobamos a aquellas en las que, exhibiendo distintos grados de dedicación, la agricultura no está en un proceso regresivo. Sin embargo, en cuanto a la base territorial utilizada, sí presentan comportamientos distintos:

- Ganaderías de asignación exclusiva o mixta, en las que trabaja población joven de una manera más o menos permanente. Constituyen prácticamente la totalidad de las que, en ganadería, superan la U.T.A. Utilizan parcelas cedidas o arrendadas, normalmente de varias explotaciones. En este estado encontramos 15 de las 52 que conforman el grupo.

- En otros ejemplos la ganadería no es la función prioritaria del caserío. Horticultura, floricultura, sidrería, agroturismo y granjas intensivas son las labores desarrolladas. Limitan sus usos a la superficie necesaria para esta actividad dejando el resto de terrenos a terceros si bien, en algún caso, lo mantienen utilizando una carga ganadera muy marginal. En esta situación se encontraban 14 caseríos.

- Un último grupo lo componen vaquerías que se aproximan a la U.T.A. Generalmente ostentan asignación parcial y suelen utilizar parcelas alquiladas o cedidas pero su base territorial principal la constituye su propia heredad. Tienen similitudes con el grupo que presentaba una función ya regresiva pero en este caso algún miembro de la familia no jubilado continúa manteniendo una actividad estable. En este conjunto localizamos 23 explotaciones.

- La de aquellas explotaciones que se encuentran indecisas ante su futuro. Muestran poca actividad y su base territorial la constituyen los suelos que tienen en propiedad, aunque en algún caso utilizan terrenos cedidos. Están en un momento expectante, pendientes de que algún familiar quiera continuar. Es población en edad de jubilación y, de no haber nadie interesado en mantener la ocupación, la abandonarán progresivamente. Hacen un total de 7 casos.

Cara a un planteamiento del futuro de los usos del suelo agrícola hemos de tener en cuenta que tan sólo 15 caseríos en Usurbil, de un total de 137, van a utilizar parcelas de otros. Es más, excepto un grupo de explotaciones que a medio plazo va a conservar una actividad algo inferior a una U.T.A. pero suficiente para proseguir con el uso actual de su heredad (23 casos), en el resto la ocupación ganadera se va a ir marginalizando progresivamente, e incluso en los primeros tampoco parece que a largo plazo se seguirá con las labores ganaderas.

Las necesidades de suelo que plantea el ganadero que continuará, sus posibilidades de mano de obra y el modelo de alimentación que elija van a repercutir en un mayor o menor abandono. Se convierten en caseríos estratégicos para el mantenimiento del suelo agrícola útil y, aún así, es más que probable que su demanda sea insuficiente para conservar el uso de la superficie actual. 


\subsection{Los servicios de ensilado de hierba en continuo crecimiento}

El suelo agrícola utilizable de la comarca es destinado preferentemente a la obtención de hierba para forraje. La pradera se convierte en el elemento que caracteriza a su paisaje rural y de su persistencia depende la continuidad de los aprovechamientos actuales. Si cara a un planteamiento de futuro de este espacio la actitud que tomen las explotaciones consagradas es trascendental, el equilibrio actual recae en gran medida en la configuración de toda una serie de prestaciones que contribuyan a mantener este uso. Su análisis nos ayudará a comprender cómo se sostienen estos aprovechamientos, qué evolución han presentado y qué perspectivas presentan.

En la comarca, las entidades de desarrollo agrícola y los ayuntamientos, a petición de los ganaderos de la zona, han puesto en marcha distintos servicios de ensilado de hierba. El modelo potenciado consiste en dotar a una persona que posea un tractor de una cilindrada mínima de la herramienta necesaria para realizar esta labor, normalmente una rotoempacadora y una encitadora.

La iniciativa parece responder, en primera instancia, a una demanda de un modelo de ensilado enormemente cómodo, cuya maquinaria resulta muy costosa, injustificable para una explotación que, salvo contadas excepciones, no realiza más de 100 bolas de hierba anuales. Una vez puesto en marcha, su utilización se incrementa hasta el punto de convertirse en un elemento de referencia fundamental en el estudio de los usos del suelo agroganadero de la comarca puesto que esta máquina siega y ensila el forraje de la mayoría de los caseríos que disfrutan de esta prestación.

Con el objeto de observar la situación del espacio mecanizable, hemos procedido a analizar la labor de uno de estos servicios en la comarca, concretamente, el que opera en los municipios de Rentería y Oiartzun. Según la información aportada por el propio maquinista, comienza a funcionar en la campaña de 1997. Ese año realiza un total de 1.618 bolas de hierba. En 1998 son ya 2.492 bolas y en 1999 3.541. Este último año, además, inicia su trabajo la segadora y en número de horas se aproxima a la mitad de las del trabajo de ensilado.

El demandante concuerda con la tipología de explotación que tiende hacia la marginalización. Contrastando los datos recogidos en 1998 con los de la campaña de saneamiento de ese año, al menos los relativos a bovino de carne y de leche, observamos que de 133 explotaciones que utilizaron el servicio sólo 8 superan la U.T.A. de equivalencia en actividad ganadera. Se ha de suponer que la mayoría de estas unidades están lideradas por activos de edad avanzada o por población que tiene la actividad retributiva principal fuera de la explotación.

El análisis de las fechas de ensilado y del número de veces que lo realizan también aporta un dato interesante. En Oiartzun, el maquinista efectúa 84 salidas en 1999, de las que 51 corresponden a la primera siega, consumada esa campaña entre mayo y mediados de junio. Si tenemos en cuenta que son 60 las explotaciones que han recibido la prestación y tan sólo 20 la han vuelto a requerir a partir de la segunda cosecha, llegamos a la conclusión de que en Oiartzun mayoritariamente se da un único corte a la hierba y después el terreno es utilizado como pasto. Por tanto, el suelo mecanizable, que permite entre 3 y 4 siegas al año, parece estar ya orientado hacia un uso más extensivo, produciéndose una pérdida de unidades forrajeras por hectárea considerable ${ }^{6}$.

6 El máximo se obtiene del primer corte, aunque no necesariamente el mayor número de unidades forrajeras por hectárea. Los cortes siguientes van disminuyendo masivamente en producción (FERRER et al., 1990, p. 47). 
En Rentería, el mismo maquinista materializa 124 salidas. En total son atendidos 57 caseríos distintos pero únicamente repiten 22. En este caso, se produce la misma situación que en Oiartzun, con un número mayoritario de explotaciones realizando una única recolección.

La entrevista con el maquinista permite profundizar en la evolución de los aprovechamientos de estos terrenos. Según él, gracias a esta prestación el suelo mecanizable mantiene su uso forrajero. El alimento obtenido permite conservar una reducida cantidad de ganado que recibe como sustento exclusivo el heno ensilado, además de la hierba cortada a diente ${ }^{7}$.

Sin embargo, observa que la situación es transitoria. Por un lado, señala cómo este proceso de extensificación es reciente, principalmente desarrollado en los últimos cinco años. La parcela no laborable no recibe más carga que la del ganado que lo aprovecha, a menudo insuficiente, y en determinadas zonas dentro de la misma parcela se observan los primeros síntomas de abandono ${ }^{8}$. En algunos casos, los menos, lo que no es consumido por el ganado lo desbroza el mismo propietario. Por otro lado, la tendencia a solicitar la prestación completa, corte y ensilado, es generalizada. La siega a mano casi ha desaparecido e incluso la mecánica no motorizada está perdiendo importancia. El jefe de la explotación tiene una edad muy avanzada para segar el terreno mecanizable y los hijos ni quieren ni colaboran en el corte y en ensilado.

Apunta distintos pasos en este proceso. En primer lugar, normalmente se sustituye el bovino de leche por el de carne, a menudo acompañado con un pequeño rebaño de varias decenas de cabezas de ovino. En un segundo momento, se opta por reducir el de carne y mantener el ovino y finalmente, cuando los suelos van perdiendo su capacidad productiva, se cede la parcela para el mantenimiento y limpieza a un tercero ${ }^{9}$. Actualmente, la mayoría de las explotaciones se situarían entre el primer y el segundo paso. Considera también que a medio o largo plazo los mejores terrenos mantendrán su uso forrajero, interesantes todavía para el ganadero profesional. Sin embargo, los más marginales, los no laborables, a medida que se vaya consumando el cambio generacional tal vez pierdan su utilidad agrícola.

Los datos relativos al servicio de siega y ensilado completan los obtenidos en el municipio de Usurbil. El proceso de infrautilización de usos es paralelo al de la extensificación de actividades y, previsiblemente, el abandono de la función agrícola reducirá los suelos utilizables.

7 En contra de lo señalado en otras investigaciones, que resaltan la importancia del consumo de piensos en el ganado que pasta a diente, observamos cómo la alimentación, una década después, se hace exclusivamente a base de hierba ensilada en invierno y hierba cortada a diente entre primavera y otoño en muchas explotaciones, principalmente en aquellas que poseen una cabaña muy reducida, acorde a la capacidad energética que puede aportar su explotación.

8 En este sentido, AMELLA et al. señalan que «pueden darse situaciones de infrapastoreo por permitir al ganado seleccionar en demasía, lo que redunda en un desarrollo diferencial de unas especies y otras, en beneficio de las menos valiosas, con el consiguiente empobrecimiento del pasto en su conjunto» (1990, p. 81). LASANTA y ERREA se refieren también al efecto de la subexplotación del pastoreo, observando una degradación progresiva de su calidad conforme la vegetación gana estructura leñosa y pierde tallos herbáceos (1997, p. 60).

9 La situación habitual suele estar constituida por una presencia permanente de vegetación caduca, por relativo abandono de la parcela, que impide el rebrote y desarrollo de especies de buena capacidad forrajera. Resulta imprescindible desbrozarla en primavera para permitir regenerar el pasto. Una vez que el abandono ya es más evidente se ha de recurrir a medidas drásticas y costosas como los herbicidas (AMELLA et al., 1990, p. 103). 


\subsection{La extensificación y el abandono se materializan: el caso de Hondarribia y Oiartzun}

Hemos optado por éstos porque según el censo agrario de 1999 mostraban un mayor número de explotaciones menores de $1 \mathrm{Ha}$. (Hondarribia) y, según la campaña de saneamiento de 1998, un proceso de extensificación ganadera, si cabe, más acentuado (Oiartzun). Sin embargo, no utilizamos la entrevista directa. Dirigimos nuestra atención a observar la evolución de los usos del suelo tomando como referencia al barrio o al municipio. Para ello, concertamos una serie de reuniones con los «alcaldes de barrio», personas que le representan y que forman la comisión de la zona rural, que todavía pervive en estos ayuntamientos.

En Hondarribia, el espacio agrícola utilizable está constituido básicamente por pastos permanentes que, en la mayoría de los casos, mantienen su uso forrajero habitual (prado o pasto). Sin embargo, encontramos por primera vez indicios evidentes de explotaciones cuya heredad muestra un alto grado de subexplotación e incluso de abandono. Este estado lo hemos observado en ocho caseríos aunque parece responder a un proceso que irremediablemente se irá consolidando en los próximos años.

Es una situación reciente, visible en los últimos dos años, en la que los prados y pastos van dejando paso a la hierba alta y al matorral. Responde a una evolución similar a todos ellos que, partiendo de una base productiva totalmente mecanizable, presenta las siguientes fases:

- Hasta iniciarse la década de los noventa estos terrenos eran praderas de las que se obtenían anualmente entre tres y cinco cortes de hierba. El ganado, salvo en zonas concretas, no pastaba en estos campos. En la mayoría de los casos los explotaba directamente el propietario o algún vecino mediante cesión. Nos situamos en un caserío especializado en vacuno de leche, con un espacio productivo dominado por la pradera aprovechada a siega y con una presencia mayoritaria como especie forrajera más importante del lolium multiflorum, o ray grass italiano.

- Progresivamente, el ganado, tanto vacuno como ovino, comienza a pastar en estos terrenos. El disfrute a diente se completa con un corte anual. Todavía algunas explotaciones utilizan las parcelas exclusivamente para prado, aunque esta situación sólo la encontramos en dos casos. Se consuman más abandonos pero el aprovechamiento de la heredad es cedido a terceras personas y no hay espacio agrícola en desuso.

- En los dos últimos años de la década de los noventa los terrenos de cuatro de estas explotaciones son abandonados y el de las otras infrautilizados, bien con ovino bien con bovino. En todos ellos encontramos forraje sin cortar y aparecen las primeras matas de matorral ${ }^{10}$.

La razón principal que lleva al desuso de la superficie mecanizable es la falta de mano de obra familiar o vecinal dispuesta a aportarle una utilidad adecuada. En cinco ejemplos se trata de población envejecida que carece de continuidad, incapaz de sostener el aprovechamiento de sus terrenos o de aquellos que manejaba en régimen de cesión o arrendamiento. Normalmente deja estos últimos y mantiene algo de carga ganadera en los suyos, insuficiente para evitar la pérdida de la capacidad forrajera de ese suelo. En otros, es per-

10 En la comarca observamos sobre todo, en función del substrato, la aparición de aliagas, brezo, helecho e incluso enebros y tojo, y a los que se les pueden añadir toda una serie de especies de bajo porte, que denuncian un estudio cercano al matorral brezo-helecho, como cañuelas, cuernecillos y gencianas. 
sonal en edad activa que carece de tiempo para mantener una cabaña ganadera y el uso forrajero de su heredad y, o la infrautiliza, o la abandona. En un último, otro tipo de razones son las que han llevado al deterioro del caserío (quiebra financiera). El nuevo inquilino, neo-rural, no le aporta ninguna utilidad productiva al terreno de su propiedad ${ }^{11}$.

Observamos que en Hondarribia apenas hay ganaderos de dedicación exclusiva. Si la cesión o arrendamiento ha funcionado hasta nuestros días, con la jubilación y pérdida de los pocos agricultores que se mantienen en activo se ofertan terrenos que ahora ya no se aprovechan. Es más que previsible que en los próximos años, a medida que estos ganaderos abandonen toda actividad, la pérdida de espacio agrícola utilizable se generalice.

Aprovechando la entrevista con los alcaldes de barrio, recogemos los usos del suelo que en los barrios de Akartegi y Montaña de Hondarribia había en el año 1990 y en el año 2000. Los aprovechamientos actuales han sido obtenidos a partir de la observación de estas superficies y los de 1990 a partir de las referencias de la población local.

De los cambios recogidos resalta el paso de la pradera al pastizal al que, por lo general, se le aporta un único corte anual, aunque también hay parcelas que ahora pasan a ser segadas exclusivamente a diente. Los pastizales ubicados en zonas con menos posibilidades agrícolas son, en este período, mayormente descuidados. Se inicia en ellos un proceso de regeneración natural, combinándose con las gramíneas, aliagas, helechos y especies de porte leñosos. También algunos prados entran en desuso directamente aunque éstos son los menos. La superficie dominada por el matorral o el monte bajo apenas aumenta y si lo hace es a cuenta de algunas parcelas de pastizal que ya estaba semiabandonado en el período anterior o por algún pinar que tras su tala no ha sido repoblado.

Oiartzun presenta un estado distinto y, aunque todo parece indicar que el proceso será similar al de Hondarribia, esta realidad todavía no es tan evidente. En este caso concreto hemos centrado nuestra investigación en los barrios de Karrika e Iturrioz. Se han tomado un total de 15 muestras dirigidas a recoger los ejemplos más críticos aunque, al igual que en Hondarribia, aquí también tenemos la impresión de que la situación es generalizada. Todos son casos recientes que señalan la evolución de estas explotaciones en los últimos cinco años.

En estos caseríos todavía se mantiene el uso forrajero de los terrenos que han constituido en los últimos años el espacio agroganadero de la explotación, tanto mecanizable como no mecanizable. Sin embargo, son varios los elementos que indican que la situación observada en Hondarribia tal vez pueda repetirse en este caso:

- El primero es la falta de población activa joven. La única mano de obra disponible es la de población jubilada o próxima a jubilarse. Esta última combina su actividad con un empleo en el exterior. En algunos casos cuentan con algo de ayuda familiar, normalmente hijos que ya trabajan fuera de la explotación pero que apenas colaboran en su marcha.

- Otro elemento coincidente es el paso de vacuno de leche a carne. Este se ha producido en 11 casos, mientras otros cuatro abandonaban toda actividad agroganadera.

11 La situación de las parcelas forrajeras es muy variada y como señalan FERRER et al. «no tanto como consecuencia de los factores ecológicos estáticos (clima, suelo, topografía) sino en función de los factores dinámicos o bióticos, y más concretamente antrópicos (antigüedad de la pradera, cuidados recibidos, empleo de fertilizantes, influencia del ganado, mezclas de semillas utilizadas, ...)» (1990, p. 22). 
El paso de leche a carne no ha supuesto un aumento del número de cabezas, al contrario, en todos ellos se ha reducido. La carga ganadera mantenida es marginal, en 9 de los 11 casos inferior a 5 vacas de carne.

La dinámica que descubren los usos del suelo agrícola utilizable indica que el proceso de abandono todavía no está tan avanzado; en ocho muestras le aportan un corte al terreno mecanizable (bolas de hierba) y después aprovechan la heredad a diente; en cuatro han cedido el uso a terceros; en otras dos utilizan el terreno para pasto y la siega la realiza un tercero a cambio de una parte proporcional del forraje obtenido; en un caso se consume directamente, sin ninguna corta.

Los cambios acaecidos en los usos del suelo entre 1990 y 2000 en el barrio de Karrika, muestran el proceso de extensificación generalizado al que hacemos referencia. Aquí también la alteración principal se produce como consecuencia del paso de prado a pasto a siega (una corta) o a diente. En este caso, las zonas en desuso son escasas y se reducen a pequeñas parcelas marginales. Las áreas de cultivo y frutales mantienen su anterior superficie e incluso, a pesar de haber sido abandonada alguna pequeña parcela, el helechal conserva su uso. Se constata también el descuido de algunos terrenos ocupados por pinares, que ahora pasan a constituir básicamente monte bajo y tampoco se observan nuevas superficies repobladas con pino.

Con una situación algo distinta a la de Hondarribia, el barrio de Karrika muestra los efectos de la extensificación ganadera que se ha producido en esa década. Es previsible que la evolución, sin embargo, sea similar, si bien la existencia de explotaciones al frente de las cuales se sitúa población joven, en este caso especializadas en ovino, parece ser garantía de mantenimiento de gran parte de los usos actuales.

\subsection{El ganadero que continuará no demandará tierra}

Con el objeto de analizar las estrategias territoriales que presentan los ganaderos con una continuidad manifiesta hemos procedido a realizar un número reducido de entrevistas dirigidas a los titulares de los distintos modelos de explotaciones que observábamos, centradas en cuatro cuestiones diferentes: necesidad actual del suelo, demanda planteada a medio plazo según el proyecto que quieran liderar, oferta actual y futuro del terreno utilizable y cambios que observan en los usos del suelo del espacio agrícola.

Vacuno de leche: aporte alimenticio exterior

La utilización de piensos y compuestos ha sido una constante en la alimentación del vacuno de leche del caserío vasco, necesaria para completar el aporte energético obtenido a partir del forraje de la propia explotación, en un momento en el que la cabaña ganadera aumenta. En la actualidad, normalmente, la alimentación se realiza a través de silo de hierba y heno de hierba que se recoge en la propia explotación y que se completa con aportes exteriores, principalmente alfalfa, pulpa granulada, semilla de algodón y pienso compuesto.

A partir de 1998 un reducido grupo de explotaciones de vacuno de leche de la comarca opta por la utilización masiva de aprovisionamiento exterior y reciben diariamente en su propia casa los alimentos ya mezclados que el ganado va a consumir. No toda la cabaña es mantenida mediante este sistema. Al lote que no está en producción, principalmente novi- 
llas, se le sustenta exclusivamente con heno y silo de hierba ${ }^{12}$. La hacienda es estabulada permanentemente y el aumento de la cabaña ganadera ya no está condicionado por la superficie agrícola utilizada.

En nuestro caso, hemos procedido a entrevistar a dos explotaciones que representan a un $10 \%$ de aquellas que continuarán a largo plazo en esta actividad. Tienen una media de 130 cabezas de ganado, con 70 vacas de leche de ordeño. Son unidades familiares y en un caso también forman una comunidad de bienes. La superficie agrícola media utilizada es de $38 \mathrm{Ha}$., de las que 28 son mecanizables, preferentemente prados, a las que aportan alrededor de tres cortes de hierba anuales. A pesar de contar con una carga ganadera importante, en sus planes de futuro, al menos en un caso, se plantea aumentar la vaquería, pasando de 80 a 120 reses en ordeño.

Como se observa la base territorial utilizada es considerable, si bien está dedicada preferentemente al sustento de los animales que no están en producción ${ }^{13}$. Consultados ante la necesidad de más terreno su respuesta es negativa. Utilizan suficiente suelo agrícola y, a pesar de contemplar en sus planes un aumento de la capacidad productiva, no se plantean emplear más.

Tampoco ven una oferta excesiva de terreno ni creen que la vaya a haber en el futuro. Al parecer, las únicas parcelas que se les ofrece suelen ser las que peores condiciones presentan o las que se encuentran en un estado de desuso avanzado, y no les interesan. Tampoco realizan mejoras en éstas, que sólo cortan y abonan.

De cara a la situación que se presenta, creen que el terreno laborable se mantendrá con un uso similar al actual. El no mecanizable, sin embargo, sí se puede perder, situación que uno de los entrevistados da como segura.

Por tanto, estamos ante una unidad productiva que no va a crecer en base territorial. Es más, en este momento es el modelo más avanzado, al que se han incorporado la mayoría de las explotaciones que tradicionalmente han sido referencia obligada en la comarca para el resto de las especializadas en bovino de leche ${ }^{14}$.

Vacuno de leche de base forrajera

Hemos entrevistado a cinco ganaderos que representarían a unos 60 caseríos especializados en bovino de leche. En los últimos años han consolidado su estructura productiva,

12 En este sentido se pronuncia AGORRETA, veterinario de la cooperativa Sergasi, quien señala que «lo que se suele hacer es suministrar el forraje propio a las novillas y al lote con baja producción, y dedicar la mezcla (básicamente concentrados y subproductos que no provocan rumia) al lote de alta producción. De esta manera se está trasladando el coste de la recría al de la producción» (ARDATZA, nº 274, 1999, p. III).

13 «El escaso aprovechamiento de las posibilidades productivas de la pradera es una situación habitual en un caserío que ha mostrado una gran inquietud en la aplicación de las mejoras técnicas (instalaciones, sanidad, inseminación, ...) mientras que los pastos se siguen aprovechando a partir de ideas y métodos arcaicos» (AMELLA, et al., 1990, p. 104).

14 Es difícil predecir si este modelo incorporará más explotaciones. Los problemas territoriales de los caseríos de la comarca, la tendencia a aumentar la capacidad productiva y la tipología de las que se han incorporado a la iniciativa indican que la tendencia irá en aumento. Sin embargo, investigaciones que analizan esta problemática a nivel general no creen que vaya a desarrollarse mucho más. En este sentido, CALCEDO señala que «no es posible que su potencial para producir a bajo coste y, por tanto, competir pueda erosionarse en pro de la explotación básicamente intensiva con alto consumo de piensos concentrados, aunque éstos se abaraten. No debe ignorarse que ya asoma la tendencia a la extensificación y a la mejora del medio ambiente, bajo la presión de la reforma de la P.A.C., que juega a su favor» (1995, p. 103). 
han aumentado su carga ganadera y muestran una continuidad a medio-largo plazo contrastada.

El modelo de explotación, sin embargo, a pesar de tener una base común dista mucho del anterior. Muestran una media de 25 vacas en ordeño y aproximadamente unas 40 en total. Son explotaciones con mano de obra dedicada a tiempo exclusivo a la actividad, de estructura familiar, aunque en general es una única persona de alrededor de 40 años la que realmente lleva la responsabilidad. La S.A.U. media es de 17,6 Ha., de las que mecanizables son 11,2 Ha. y no mecanizables 6,4 Ha. En propiedad tienen unas 6 Ha. de media y el resto es arrendada.

Entre sus planes de futuro se contempla un aumento de la cabaña ganadera, si bien éste parece ser muy relativo, de unas pocas cabezas más de las que tiene actualmente. Podíamos cifrarlo en un paso a una cabaña media de 30 vacas en ordeño.

En este caso tampoco se plantea una necesidad evidente de más terreno. Por lo general, cuentan con una base forrajera suficiente y no prevén que necesiten mucha más. De utilizar suelo de terceros ha de ser laborable, si bien en algún caso aceptarían suelo no mecanizable siempre y cuando esté próximo a su explotación.

Respecto a la situación que observan en los usos del suelo agrario de sus proximidades opinan que el terreno laborable se mantendrá. El de más desnivel, sin embargo, y especialmente en los casos en que esté lejos de las explotaciones, perderá su uso agrícola y se abandonará. De hecho, apuntan que los terrenos que se les oferta ya no presentan unas condiciones adecuadas para su uso ya que, por lo general, son suelos que comienzan a ser invadidos por la maleza. Cabe señalar que tampoco parecen tener una excesiva preocupación por recuperar unas parcelas que, en muchos casos, volverían a ser reutilizables con un simple desbroce, de lo que deducimos que la necesidad de nuevas superficies no es apremiante.

En este caso, también estamos ante una explotación que, a pesar de estar fundamentada en una base forrajera, no parece necesitada de mucho más suelo agrícola. Es más, señalan que con sus posibilidades de mano de obra tampoco pueden hacer frente ni a una mayor carga ganadera ni a una mayor base territorial.

\section{Explotación de ovino}

Las explotaciones de ovino que superan la U.T.A. de equivalencia en producción, en las que figura una persona menor de 50 años al frente o ayudando en sus labores y que además hayan realizado mejoras productivas en su explotación son muy escasas en esta comarca, contabilizando apenas una decena. En este análisis hemos entrevistado a dos de ellas.

Presentan un rebaño medio de 325 ovejas y, en un caso, tienen 20 vacas lecheras. En ambas trabaja población a tiempo completo, normalmente una persona que cuenta con ayuda familiar. La S.A.U. media es de $23 \mathrm{Ha}$., de las que 14,5 Ha. son mecanizables y tan sólo $4 \mathrm{Ha}$. lo son en propiedad. Completan la base territorial utilizada con pastos de montaña estivales. El espacio mecanizable está destinado en su mayoría a la obtención de hierba ensilada y normalmente le aportan tres cortes anuales.

$\mathrm{Su}$ intención es la de mantener la actividad. Los esfuerzos van destinados a introducir mejoras técnicas pero no a aumentar la cabaña ganadera (salas de ordeño, quesería, embolsadora, ...). Sin embargo, ambos tienen una mayor necesidad de suelo que cifran, atendiendo a los usos actuales, en unas $10 \mathrm{Ha}$. 
La superficie que solicitan es preferentemente laborable, que pretenden destinar a heno. La no mecanizable también es interesante, siempre y cuando se sitúe próxima a la explotación. Se les ofertan parcelas en función de la mayor o menor presencia de ganaderos en la zona. No laborable en ambos casos pero roturable sólo en uno y tan sólo para aportarle el primer corte. Tampoco creen que este último pierda su uso forrajero. Las que más grado de pendiente ostentan, sin embargo, se abandonarán progresivamente.

Las explotaciones de ovino, por tanto, sí parecen necesitadas de nuevas parcelas, especialmente para obtener heno ensilado con el que alimentar al ganado en otoño e invierno. Además, suelen utilizar terrenos próximos a la vivienda en mayor número que el resto, al ser ganado extensivo que todavía, en algunos casos, permanece gran parte de su tiempo sin estabular.

Bovino de carne

Las explotaciones de bovino de carne que actualmente superan una U.T.A. de equivalencia en producción no alcanzan la treintena en la comarca. En esta muestra hemos entrevistado a dos ganaderos, con explotaciones ubicadas en el municipio de Lezo. La S.A.U. media es de 17,5 Ha., de las que laborables serían alrededor de $12 \mathrm{Ha}$. En propiedad tienen una media de 4,6 Ha. y el resto del terreno es arrendado o cedido. En ambos casos, además, realizan labores de engorde de terneros, con una cabaña media de 42 cabezas. El aprovechamiento principal de estos suelos es forrajero, normalmente prados, de los que obtienen entre 3 y 4 siegas anuales.

En las condiciones actuales no apuestan por realizar grandes ampliaciones de su vaquería. El tiempo que poseen es limitado y en sus pretensiones estaría el mantener o aumentar ligeramente su explotación actual. Sin embargo, ambos señalan la necesidad de más suelo, siempre mecanizable o, en todo caso, próximo a la vivienda, aunque cifran ésta en $5 \mathrm{Ha}$. de media. No aceptarían, sin embargo, pagar una renta por nuevos terrenos por lo que consideramos que tampoco tienen una necesidad de suelo apremiante.

Les han ofrecido parcelas recientemente, incluso en un caso desde municipios colindantes (Hondarribia), aunque en general observan que apenas hay terreno sin utilizar y aquellas parcelas que pudieran quedar libres se las han repartido entre 3 explotaciones en este municipio. Sin embargo, sí señalan que en un período de 10 años muchas van a perder su uso actual puesto que no ven continuidad en un gran número de unidades productivas en las que el titular es mayor de 60 años. Observan que la parcela que permite su manejo con maquinaria agrícola aún así no perderá su utilidad forrajera, siempre y cuando la ofrezcan para su mantenimiento pero, sin embargo, el no mecanizable sí se abandonará.

A tenor de estas dos muestras, este grupo previsiblemente aumentará su superficie utilizada, aunque dada su escasa disponibilidad de tiempo tampoco pueden aprovechar mucho más del que disfrutan actualmente. De ampliar la base productiva todo indica que lo hará a cuenta de terreno mecanizable pues el no mecanizable no parece interesarle.

\section{Extensificación actual y pérdida de suelo futura}

Las aportaciones que hemos ido realizando a lo largo de este apartado nos sitúan ante unos usos del suelo que presentan los primeros indicadores de un nuevo escenario. El detonante del proceso es la falta de mano de obra que trabaja en la agricultura bien porque la generación más joven no continúa con esta actividad o bien porque no tienen ayuda fami- 
liar suficiente para hacer frente a un aumento de producción que requiera mayor número de horas trabajadas. La ausencia de activos también se evidencia en aquellas explotaciones de asignación exclusiva al frente de las cuales encontramos a un joven agricultor que ha iniciado una estrategia tendente a incrementar la capacidad productiva. A menudo, tan sólo cuenta con la ayuda de unos padres ya mayores y en muchos casos el cónyuge no colabora en las labores del caserío. A pesar de que inicia acciones para aumentar sus rendimientos, éstas se limitan a una modernización o, en todo caso, a un aumento de la cabaña a partir de aportes alimenticios exteriores.

En el proceso de marginalización y abandono de la actividad, a la vez que se apuesta por formas más extensivas de ganadería, los aprovechamientos evolucionan paralelamente. Aún así, existen al menos dos elementos que actúan como freno ante el progresivo abandono que parece observarse en el manejo del suelo agroganadero.

- Los servicios de ensilado ayudan a mantener el aprovechamiento forrajero del espacio mecanizable. El sistema de ensilado mediante bolas de hierba y la utilización de la segadora-acondicionadora elimina el trabajo que más tiempo, esfuerzo físico y personal requieren en la explotación y a un precio asequible. Actualmente el ganadero mantiene algo de actividad hasta edades muy avanzadas ${ }^{15}$.

- La cesión o «garbitzealde» posibilita que muchos terrenos de propietarios que carecen de actividad mantengan su uso agrícola tradicional. A cambio de la limpieza y del cuidado de estas parcelas, las explotaciones ganaderas aumentan su base territorial, su capacidad forrajera y junto a ello, su cabaña.

Sin embargo, todo parece indicar que el equilibrio actual en los usos del suelo no va a perdurar a medio o largo plazo. De hecho, se han producido los primeros abandonos en aquellos lugares en los que no hay demanda de tierra para uso agrícola. En los próximos años se va a consumar el cambio generacional y con él muchas explotaciones van a desaparecer. Esta situación, además, se acentuará si tenemos en cuenta que las ganaderías que podían beneficiarse de estas parcelas, en la mayoría de los casos, no parecen requerir más espacio utilizable. Presumiblemente, la demanda va a ser mucho menor que la oferta de terrenos a utilizar y la pérdida de suelo agrícola se va a consumar ${ }^{16}$.

El escenario descrito previsiblemente se generalizará, si bien es posible que se establezcan diferencias entre unas y otras zonas. En principio, aquellas que tienen una mayor concentración de explotaciones ganaderas de entidad, con una continuidad manifiesta, mantendrán gran parte del uso y espacio forrajero actual. Las que carezcan de este tipo de

15 Situación, por otra parte, muy observada en todo el medio rural. En el caso de Galicia, LÓPEZ IGLESIAS señala que «estos agricultores prolongan normalmente su actividad mucho más allá de la edad habitual de jubilación (65 años), retardando de este modo la desaparición de las unidades productivas» (1996, p. 494).

16 Hemos señalado que muchas regiones de montaña se encuentran ante un proceso de estas características. En otras zonas apenas se ha iniciado pero, como en el caso del Pirineo Aragonés, todo parece indicar que también esta situación es inminente. En este sentido LASANTA et al. señalan que «la situación actual, por el contrario, revela que ya no se utilizan de forma intensiva ni los mejores espacios; éstos han empezado a subutilizarse, lo que a corto o medio plazo puede llevar al abandono de parte de los prados, o en el caso de que se mantengan en cultivo a aprovechar aún menos los campos abandonados y las laderas bajas e incluso a no subir el ganado a los puertos. De alguna manera, se puede prever que el espacio utilizado por las actividades agropecuarias corre el riego de contraerse en el futuro próximo, experimentando un proceso de colonización por formaciones de matorral que disminuirían la densidad y calidad paisajista sin mejorar sensiblemente la composición del suelo» (1998, p. 435). 
unidades productivas retirarán más rápidamente estos usos puesto que, junto con el abandono de las de su propiedad, dejará las que mantenía a cambio de su limpieza.

Diferencias también se establecerán según la capacidad agrológica del suelo. El laborable es posible que conserve su aprovechamiento pero siempre en aquellas zonas o municipios en los que existan explotaciones que demanden suelo. En otros se reducirá. El no mecanizable, sin embargo, muestra un futuro muy incierto y, excepto en aquellos casos lindantes con ganaderías, la mayoría de los terrenos con pendientes superiores a un 20-25\% perderán su uso agrícola.

Las transformaciones observadas coinciden con las que se están materializando en las áreas de montaña, aunque presenta una serie de características que le confieren en este caso un desarrollo peculiar. En principio, el fenómeno más generalizado no es la concentración e intensificación de los usos en los fondos del valle o en las zonas agrícolas próximas sino que, incluso en éstas, se da un proceso de extensificación e infrautilización mayoritario.

El uso tradicional desde mediados de la década de los sesenta, el aprovechamiento forrajero a siega o a diente, se mantiene, pero se observa una extensificación que afecta también a muchos de los terrenos que mejores condiciones agrológicas muestran. Se reduce el número de cortes, normalmente a un único anual, y el resto del año se aprovecha para pasto del ganado, cuando hace apenas una década se daban normalmente entre tres y cuatro siegas al terreno mecanizable. Así, cada vez son más numerosos los casos en los que no se le aporta ni una sola siega y un reducido número de cabezas pasta libremente todo el año.

El elemento que explica esta situación, como en otras zonas de montaña, es la falta de mano de obra agrícola para trabajar estas parcelas. Sin embargo, la causa que provoca que la extensificación sea generalizada tiene una naturaleza parcialmente distinta a la de las regiones de montaña, relacionada con la proximidad de la ciudad. El elevado precio del suelo anula la existencia de un mercado de tierras a precios agrícolas. El propietario, con unas claras perspectivas especulativas, no quiere adquirir ningún tipo de compromiso y no arrienda su heredad. Por lo general, procura mantener el aprovechamiento de sus parcelas mediante una reducida carga de ganado, con una cada vez mayor presencia del ovino, lo que provoca una extensificación generalizada de usos. En los casos en los que la heredad comienza a descuidarse en exceso, decide transferir en precario su disfrute a un tercero, que, generalmente, ni invierte ni mejora la parcela y obtiene de ella lo que le dé, manteniéndose de esta manera el provecho extensivo anterior.

Otro aspecto a reseñar es que, a diferencia de la situación generalizada que hemos observado en las zonas de agricultura de montaña, no se advierte aquí una pérdida de suelo agrícola. Sin embargo, este estadio parece ser tan sólo momentáneo puesto que ya han comenzado a intuirse los primeros abandonos y se observa cómo, producto del desuso, el matorral comienza a invadir algunos campos. Coincide, al menos en este caso, con la situación observada en las zonas de montaña pero se trata de la previsión de un proceso cuyo inicio está tan localizado y reducido a un número concreto de parcelas que todavía ha de ser tomado como un escenario por confirmar.

Asimismo, otros aprovechamientos alternativos al abandono del suelo utilizable no parece que vayan a tener apenas trascendencia. Las repoblaciones de coníferas, una vez taladas, no son de nuevo reforestadas, regenerándose un bosque de forma espontánea, caracterizado por su bajo porte y la multitud de pies. De igual manera, los pocos campos en desuso o subexplotados que hemos encontrado no son reutilizados y es el matorral el que comienza ahora a invadirlos. La falta de mano de obra es generalizada, y dado que no se 
intuye un aprovechamiento, es más que previsible que muchas zonas que tienen actualmente un uso agrícola también se incorporen a este proceso.

Por tanto, esta comarca, más que responder a un binomio intensificación-abandono o sobreexplotación-infrautilización propio de zonas de montaña, responde a una extensificación generalizada de los usos, con un mantenimiento de la superficie agrícola utilizada. Sin embargo, no es un estado estable sino una etapa más en un proceso que lleva al abandono de superficies, usos y actividades agrícolas.

\section{Bibliografía y fuentes impresas citadas}

CALCEDO ORDOÑEZ, V. (1995): «Balance de la aplicación del régimen de cuotas lecheras en la España húmeda». Revista Española de Economía Agraria, n 173, pp. 79-110. FERRER, C. et al. (1990): «La producción de hierba», en AMELLA, A. y FERRER, C. (eds.): Explotación de pastos en caseríos guipuzcoanos. Departamento de Agricultura y Pesca del Gobierno Vasco, pp. 9-53.

FERRER, C. et al. (1990b): «Estudio agrológico económico» en AMELLA, A. y FERRER, C. (eds.): Explotación de pastos en caseríos guipuzcoanos. Departamento de Agricultura y Pesca del Gobierno Vasco, pp. 203-253.

FJELLSTAD, W.J., DRAMSTAD, W.E. (1999): «Patterns of change in two contrasting Norwegian agricultural landscapes». Landscape and urban planning, $\mathrm{n}^{\circ} 45$, pp. 177191.

LASANTA MARTÍNEZ, T., SANZ TRULLEN, V. y ERREA, M.P. (1998): «Cambios recientes en la ganadería pirenaica y pérdida de recursos forrajeros». IX Coloquio de Geografía Rural. Universidad del País Vasco. Vitoria-Gasteiz, pp. 429-439.

LASANTA MARTÍNEZ, T. (1996): «El proceso de marginación de tierras en España». Erosión y recuperación de tierras en áreas marginales. Instituto de Estudios Riojanos y Sociedad Española de Geomorfología. Zaragoza, pp. 7-32.

LASANTA MARTÍNEZ, T. y ERREA ABAD, M.P. (1997): «Cambios recientes en las relaciones entre agricultura y ganadería extensiva: de la complementariedad a la dependencia de la ganadería». Polígonos, ${ }^{\circ}$ 7, pp. 47-75.

LASANTA MARTINEZ, T., ARNAEZ VADILLO, J., RUIZ FLAÑO, P. y ORTIGOSA IZQUIERDO, L. (1998): «Evolución superficial del espacio cultivado en Cameros Viejo (Sistema Ibérico) y su relación con algunos factores geoecológicos». Instituto Pirenaico de Ecología, CSIC, Jaca, Huesca. Departamento de Geografía y Ordenación del Territorio, Colegio Universitario de La Rioja, Logroño, pp. 553-572.

LÓPEZ IGLESIAS, E. (1996): Movilidad de la tierra y dinámica de las estructuras agrarias en Galicia. Ministerio de Agricultura, Pesca y Alimentación. Secretaría General Técnica. Madrid.

RUIZ URRESTARAZU, E. (1999): «Adaptación y gestión de las medidas agroambientales y de forestación en el País Vasco» Cambios en los Espacios Rurales Cantábricos tras la integración de España en la UE. Universidad de Cantabria, pp. 139-163. 